Journal for ImmunoTherapy of Cancer

\section{FcyRII (CD32) modulates antibody clearance in NOD SCID mice leading to impaired antibody-mediated tumor cell deletion}

To cite: Oldham RJ, Mockridge $\mathrm{Cl}$, James $\mathrm{S}$, et al. FCyRll (CD32) modulates antibody clearance in NOD SCID mice leading to impaired antibody-mediated tumor cell deletion. Journal for ImmunoTherapy of Cancer 2020;8:e000619. doi:10.1136/ jitc-2020-000619

- Additional material is published online only. To view please visit the journal online (http://dx.doi.org/10.1136/jitc2020-000619).

Accepted 01 May 2020

Check for updates

(C) Author(s) (or their employer(s)) 2020. Re-use permitted under CC BY-NC. No commercial re-use. See rights and permissions. Published by BMJ.

${ }^{1}$ Antibody \& Vaccine Group, Centre for Cancer Immunology, Cancer Sciences Unit, Faculty of Medicine, University of Southampton, Southampton, UK ${ }^{2}$ Southampton Experimental Cancer Medicine/CRUK Centre, Protein Core Facility, University of Southampton Faculty of Medicine, Southampton, UK

Correspondence to Professor Mark S Cragg; msc@soton.ac.uk

\section{ABSTRACT}

Background Immune compromised mice are increasingly used for the preclinical development of monoclonal antibodies (mAb). Most common are non-obese diabetic (NOD) severe combined immunodeficient (SCID) and their derivatives such as NOD SCID interleukin-2 $\gamma$-/- (NSG), which are attractive hosts for patient-derived xenografts. Despite their widespread use, the relative biological performance of $\mathrm{mAb}$ in these strains has not been extensively studied.

Methods Clinically relevant mAb of various isotypes were administered to tumor and non-tumor-bearing SCID and NOD SCID mice and the mAb clearance monitored by ELISA. Expression analysis of surface proteins in both strains was carried out by flow cytometry and immunofluorescence microscopy. Further analysis was performed in vitro by surface plasmon resonance to assess $\mathrm{mAb}$ affinity for $\mathrm{Fc} \gamma$ receptors ( $\mathrm{Fc} \gamma \mathrm{R})$ at $\mathrm{pH} 6$ and $\mathrm{pH}$ 7.4. NOD SCID mice genetically deficient in different Fc $\gamma R$ were used to delineate their involvement.

Results Here, we show that strains on the NOD SCID background have significantly faster antibody clearance than other strains leading to reduced antitumor efficacy of clinically relevant mAb. This rapid clearance is dependent on antibody isotype, the presence of Fc glycosylation (at N297) and expression of FcyRII. Comparable effects were not seen in the parental NOD or SCID strains, demonstrating the presence of a compound defect requiring both genotypes. The absence of endogenous IgG was the key parameter transferred from the SCID as reconstituting NOD SCID or NSG mice with exogenous IgG overcame the rapid clearance and recovered antitumor efficacy. In contrast, the NOD strain was associated with reduced expression of the neonatal Fc Receptor (FcRn). We propose a novel mechanism for the rapid clearance of certain mAb isotypes in NOD SCID mouse strains, based on their interaction with $\mathrm{Fc} \gamma \mathrm{RII}$ in the context of reduced FcRn.

Conclusions This study highlights the importance of understanding the limitation of the mouse strain being used for preclinical evaluation, and demonstrates that NOD SCID strains of mice should be reconstituted with IgG prior to studies of mAb efficacy.

\section{INTRODUCTION}

The growth in the numbers of monoclonal antibodies (mAb) being developed for the clinic, particularly for use in cancer, has led to the concurrent development of in vivo models enabling their preclinical evaluation. ${ }^{1}$ These models have increasingly made use of immune-compromised mice for growing patient-derived tumor xenografts and engrafting human immune or stem cells. ${ }^{23}$

Commonly used models include non-obese diabetic (NOD) severe combined immunodeficient (SCID) mice. The SCID mutation occurs in the Prkdc gene and impairs V(D) $\mathrm{J}$ recombination, leading to an absence of functional $\mathrm{B}$ and $\mathrm{T}$ cells and resulting in mice lacking endogenous IgG. ${ }^{45}$ The NOD phenotype results in reduced NK cell frequency and function and the absence of hemolytic complement activity. ${ }^{6}$ While these immunedeficient phenotypes make NOD SCID mice attractive recipients for cell transfers (such as human peripheral blood mononuclear cells (PBMC) and tumor xenografts), they may be further enhanced by additional genetic deletions such as the interleukin-2 $\gamma$-chain (NSG). ${ }^{78}$

While the effector function defects of NOD SCID mice and their related strains are often considered, one aspect regularly overlooked is $\mathrm{mAb}$ clearance, despite the fact that genetic alterations, as well as the lack of endogenous IgG in immune deficient strains, could readily impact on mAb pharmacokinetics, resulting in altered efficacy. ${ }^{9}$

The primary receptors responsible for mediating IgG mAb activity are the Fc gamma receptor $(\mathrm{Fc} \gamma \mathrm{R})$ family. It is composed of six receptors in humans and four in mice, which vary in expression pattern and affinity for IgG subclass. ${ }^{10}$ Another receptor capable of 
interacting with IgG in both humans and mice is FcRn, which is widely expressed throughout the body. The pH-dependent nature of FcRn-IgG interactions allows the receptor to scavenge IgG from lysosomes at an acidic $\mathrm{pH}$, releasing it back into the circulation at neutral $\mathrm{pH}$, providing the long in vivo half-life of antibodies. ${ }^{11-13}$

In addition to the potential issue of altered efficacy arising from the lack of endogenous IgG (and reduced competition for $\mathrm{Fc} \gamma \mathrm{R}$ with therapeutic $\mathrm{mAb}$ ) in NOD SCID mice, previous reports indicate that immunecompromised mice, such as NOD SCID and NSG, have reduced $\mathrm{mAb}$ half-life compared with related strains. ${ }^{14-16}$ More recently, it was reported that NOD SCID mice display an anomalous biodistribution of therapeutic antibodies, including reduced tumor targeting. ${ }^{17}$ This suggests further work is required to understand the limitations of these models and develop strategies to overcome their shortcomings to make more translationally relevant preclinical tumor models.

During a recent project examining the efficacy of a tumor targeting antibody in NOD SCID mice, we noted rapid $\mathrm{mAb}$ clearance of human (h) IgG1 and mouse (m) IgG2a isotypes. Using a $\mathrm{E} \mu-\mathrm{Tcl} 1 \mathrm{hCD} 20$ +tumor model we found this rapid clearance resulted in reduced efficacy of clinically relevant $\mathrm{mAb}$, such as rituximab. Employing genetically altered mice, we showed the rapid mAb clearance was dependent on the expression of the inhibitory Fc $\gamma R$, Fc $\gamma$ RII. Additionally, we identified a reduced level of FcRn expression in NOD SCID mice, leading us to propose a novel hypothesis for how mAb half-life is regulated in these strains and means through which it can be overcome.

\section{MATERIALS AND METHODS \\ In vivo experiments}

Mice used in this study were bred and maintained in local facilities with experiments approved through local ethics committees and performed according to Home Office guidelines.

\section{Generating bone marrow chimera}

Recipient mice were provided with acid water, $\mathrm{pH} 2.5$ on day -7 until 14 days after bone marrow receipt. Recipients received $1.1 \mathrm{~Gy}$ radiation on days -1 and 0 using a MultiRad 350 X-ray Irradiator (Faxitron). Bone marrow was harvested from donor mice and $3-8 \times 10^{6}$ cells injected intravenously (I.V.) into recipients. Systemic reconstitution was confirmed by flow cytometry 8-10 weeks after engraftment.

\section{E $\mathrm{TCL}-1$ tumor model}

This model has been described previously. ${ }^{18}{ }^{19}$ Briefly, $1 \times 10^{7}$ cryopreserved E $\mu$-TCL-1 transgenic (Tg) or hCD20 ${ }^{+} \mathrm{E} \mu-\mathrm{TCL}-1 \mathrm{Tg}$ tumor splenocytes were injected intraperitoneally (I.P). into recipient mice. The presence of tumor was monitored in peripheral blood. Once tumor cells $\left(\mathrm{CD} 19^{+} \mathrm{CD}^{\mathrm{mid}}\right)$ were detectable by flow cytometry, mice were treated. The white cell count was determined using a Coulter Z1 particle counter with red blood cells (RBC) lysed using ZAP-OGLOBIN II (both Beckman Coulter) or by flow cytomery using Precision Count beads (Biolegend).

\section{In vivo antibodies}

All clinical antibodies were gifted from the Southampton General Hospital oncology pharmacy. Others were produced in-house. 18B12 and Rituximab isotype variants were cloned onto the appropriate IgG framework, produced in CHO cells and purified from culture supernatant with protein A. Purity was assessed by electrophoresis (Beckman EP; Beckman) and lack of aggregation confirmed by size exclusion (SEC) high performance liquid chromatography (HPLC). Unless otherwise stated, all antibodies were administered I.P. in $200 \mu \mathrm{L}$ sterile PBS (Severn Biotech).

\section{Flow cytometry}

Flow cytometry was performed using the antibodies listed in online supplementary table 1 . Anti-mFc $\gamma \mathrm{R}$ has been reported previously. ${ }^{20}{ }^{21}$ Following staining, RBC lysis buffer was added (AbD Serotec) and cells washed before analysis on a FACS Canto or FACS Calibur flow cytometer (BD Biosciences). Alexafluor 647 labeled MST-HN and H435A Abdegs for analyzing FcRn expression were a kind gift from Prof Sally Ward (University of Southampton) and used at $5 \mu \mathrm{g} / \mathrm{mL}$ with Fc block $(2.4 \mathrm{G} 2,5 \mu \mathrm{g} / \mathrm{mL}$ ) prior to extracellular staining.

\section{Generating bone marrow derived macrophages}

The tibia and femur of mice were flushed with sterile complete RPMI (RPMI 1640 (Life Technologies), $2 \mathrm{mM}$ L-glutamine, $1 \mathrm{mM}$ sodium pyruvate, $100 \mathrm{U} / \mathrm{mL}$ penicillin, $100 \mu \mathrm{g} / \mathrm{mL}$ streptomycin (all Life Technologies), $10 \%$ fetal calf serum (Sigma-Aldrich). Cells were plated in 6-well plates at $0.8 \times 10^{6}$ cells $/ \mathrm{mL}$ in complete RPMI $+20 \%$ L929 conditioned media for 7-10 days.

\section{Determining plasma IgG concentration}

IgG concentration was determined by ELISA with reference to a standard curve of the same antibody as follows: for hIgG, maxisorp plates (Thermo Scientific) were coated with $5 \mu \mathrm{g} / \mathrm{mL}$ goat antihuman Fc-specific polyclonal antibody (Sigma-Aldrich) and blocked with PBS+1\% BSA before addition of serum for 1 hour and washing. Detection was with horseradish peroxidase (HRP) conjugated $\mathrm{F}\left(\mathrm{ab}{ }^{\prime}{ }_{2}\right.$ goat anti-hFc specific antibody (Jackson Immunoresearch). Plates were incubated with o-phenylenediamine dihydrochloride (OPD) substrate and $\mathrm{OD}_{495}$ measured using an Epoch microplate spectrophotometer (Biotek). For quantification of $\mathrm{mIgG}$, plates were coated with rabbit anti-mIgG and detected with HRP- rabbit anti-mIgG (both Jackson Immunoresearch).

\section{Heat aggregation of IgG}

Purified IgG was heated to $64^{\circ} \mathrm{C}$ for $30 \mathrm{~min}$. The aggregated fraction was purified on a superdex S200 column 
(GE Healthcare). Aggregation was confirmed by HPLC using a Zorbax GF-250 column (Agilent).

\section{Producing $\mathrm{mFc} \gamma \mathrm{RII}$ extracellular domain protein}

RNA was isolated and cDNA generated from SCID or NOD SCID bone marrow derived macrophages (BMDM) and the $\mathrm{mFc} \gamma \mathrm{RII}$ gene amplified using gene specific primers. Subsequently, the extracellular domain (residues 1-207) of $\mathrm{mFc} \gamma \mathrm{RII}$ were cloned with the addition of a $6 \mathrm{xHis}$ tag. The construct was transfected into MEXi $-293 \mathrm{E}$ cells (IBA lifesciences) and Fc $\gamma$ RII-His expressed according to the manufacturer's protocol and protein purified using a HisTrap HP column on an AKTA prime system (Both GE biosciences) and purity confirmed by sodium dodecyl sulfate-polyacrylamide gel electrophoresis (SDS-PAGE).

\section{Surface plasmon resonance analysis}

Surface plasmon resonance (SPR) was performed using a Biacore T100 system upgraded to a T200 (GE Life Sciences). For mFc $\gamma$ RII isoforms, anti-His capture antibody was immobilized on a CM5 chip (GE life Sciences). Purified Fc $\gamma$ RII-His $(10 \mu \mathrm{g} / \mathrm{mL})$ was flowed over the chip at $30 \mu \mathrm{L} / \mathrm{min}$ for capture. IgG was injected at $30 \mu \mathrm{L} /$ min. For all other analysis, IgG was immobilized via amine coupling with a target of 2000 RU. Recombinant mFc $\gamma R I I$ or $m F c R n$ (R\&D systems) was flowed over the immobilized IgG in HBS-EP +buffer (GE Life Sciences) at $\mathrm{pH} 7.4$ or pH6.0. Affinity constants were determined by analysis with Biacore Bioevaluation software assuming 1:1 binding.

\section{Quantitative PCR}

mRNA was extracted from SCID or NOD SCID splenocytes and hepatocytes using an RNeasy Mini Kit (Qiagen) and cDNA generated using a Superscript III reverse transcription kit (Life Technologies). Quantitative PCR (qPCR) was performed using GoTaq qPCR master mix (Promega) using gene specific primers, with HPRT1 as a control. Ct values were normalized using HPRT1 values and the $\Delta \Delta \mathrm{Ct}$ method used to calculate fold change.

\section{Western blotting}

Lysates were produced from $5 \times 10^{6}$ SCID or NOD SCID splenocytes and hepatocytes using RIPA buffer $(150 \mathrm{mM}$ $\mathrm{NaCl}, 1 \%$ Triton X-100, 0.5\% Deoxycholate, $0.1 \%$ SDS, $50 \mathrm{mM}$ Tris, $\mathrm{pH} 8$ ) and run on a $12 \%$ Novex Nupage BISTRIS gel (Thermo Fisher) before transfer to a methylcellulose membrane (GE Lifesciences). Primary antibodies were antimouse FcRn and Lamin B with detection using an HRP-conjugated donkey anti-goat antibody (online supplementary table 1 ).

\section{Immunofluorescence}

Liver tissue from BALB/c or NSG mice was embedded in OCT (CellPath) and frozen in isopentane on dry ice. 8 $\mu \mathrm{m}$ sections were cut and transferred to Superfrost plus slides (Thermo Scientific), air dried overnight and fixed in $100 \%$ acetone. Following blocking, primary antibodies against FcRn or Fc $\gamma$ RII were added overnight before detection with Alexafluor 488-labeled secondary antibody (online supplementary table 1) for $45 \mathrm{~min}$. Subsequently, primary antibodies against $\mathrm{Clec} 4 \mathrm{~F}$ or cytokeratin 8 were added for 2 hours before detection with AlexaFluor 549 or AlexaFluor 568 conjugated secondary antibodies (online supplementary table 1). Slides were mounted using Vectashield hardset with 4',6-diamidino-2-phenylindole (DAPI; Vector Laboratories).

Images were collected using a CKX 41 inverted microscope with a reflected fluorescence system equipped with a DP22 camera running CellSens software, using Plan Achromat $10 \times 0.25$ and $40 \times 0.65$ objective lenses (all from Olympus). Images were transferred to ImageJ (Fiji) or photoshop (Adobe) where background autofluorescence was removed, contrast stretched and brightness adjusted to maximize clarity, with all images treated equivalently.

\section{RESULTS \\ Antitumor mAb therapy is less effective in NOD SCID mice due to rapid antibody clearance}

To explore potential differences of recipient mouse strains on immunotherapy efficacy, SCID and NOD SCID mice bearing established hCD20 $0^{+} \mathrm{E} \mu-\mathrm{TCL}-1$ tumors were treated with rituximab. Although initial tumor clearance was comparable between strains, 14 days after mAb treatment there were significantly more tumor cells in the peripheral blood of NOD SCID compared with SCID mice (figure 1A,B). To determine if this was associated with rituximab's type I nature,${ }^{22} 23$ we repeated the experiment with the type II anti-hCD20 mAb, BHH2, ${ }^{18}$ and observed the same reduced efficacy in NOD SCID compared with SCID mice (figure 1B).

To understand this difference in efficacy, the concentration of injected hIgG in the plasma of mice following treatment was determined (figure 1C). This revealed that 7 days after $\mathrm{mAb}$ treatment there was significantly less ( 10-fold) hIgG in the plasma of NOD SCID compared with SCID mice ( $16.7 \mathrm{vs} 1.6 \mu \mathrm{g} / \mathrm{mL}$ ) suggesting that rapid hIgG1 clearance in NOD SCID mice was responsible for the less prolonged tumor deletion.

To investigate whether the rapid clearance was related to the mAb, strain and/or tumor, an alternative hIgG1 $\mathrm{mAb}$, cetuximab, was administered to non-tumor bearing SCID and NOD SCID mice. Cetuximab was also more rapidly cleared from NOD SCID compared with SCID mice with hIgG being undetectable in the plasma of NOD SCID mice by day 7 post-administration (figure 1D). Similar results were also observed with other hIgG1 mAb including trastuzumab (online supplementary figure 1 ), showing that the rapid clearance is directly related to the NOD SCID strain, independent of tumor and a common feature of therapeutically-relevant hIgG1 mAb. Importantly, the hIgG1 clearance in SCID and NOD mice was comparable to that of immune-competent $\mathrm{BALB} / \mathrm{c}$ mice (online supplementary figure 2 and previously shown ${ }^{24}$ ), confirming fast hIgG1 clearance in NOD SCID mice, rather than slow clearance in SCID or NOD 


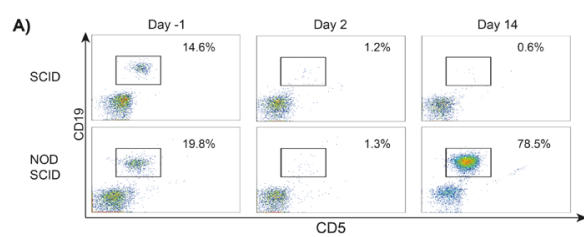

B)

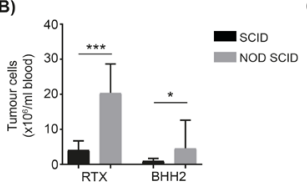

D)
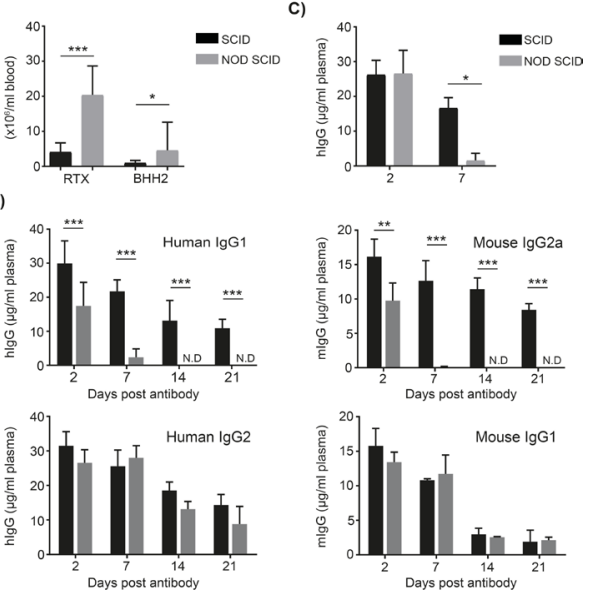

- scio nod SCID
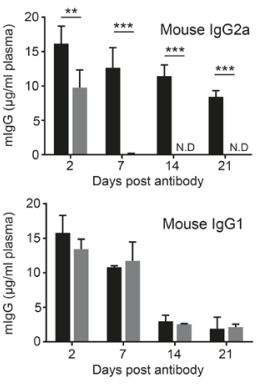

Figure 1 Antibody mediated therapy is reduced in NOD $\mathrm{SCID}$ mice due to faster mAb clearance. $(\mathrm{A}-\mathrm{C}) \mathrm{E} \mu$ - $\mathrm{Tcl} 1 \mathrm{x}$ hCD20 Tg tumor cells were injected I.P. into SCID or NOD SCID mice. Once tumor was detectable in the peripheral blood animals were treated with $100 \mu \mathrm{g}$ rituximab or $\mathrm{BHH} 2$ I.P. (A) 2 and 14 days after treatment, the percentage of tumor cells in the blood was assessed. (B) The number of tumor cells in the blood 14 days after treatment was determined $(n=4-9)$. (C) The concentration of hlgG in the plasma was measured by ELISA with a significantly lower concentration of hlgG on day 7 in NOD SCID compared with SCID mice. hlgG was not detectable in the plasma of NOD SCID mice from day 14 onwards. (D) In the absence of tumor, $100 \mu \mathrm{g}$ cetuximab or $100 \mu \mathrm{g}$ rituximab hlgG2, mlgG2a or mlgG1 was administered I.P. to SCID or NOD SCID mice. The concentration of human or mouse IgG in the plasma was determined by ELISA. (hlgG1 $\mathrm{n}=6-7$; combined data from two independent experiments, hlgG2, mlgG1 and mlgG2a $n=3$, representative of 2 independent experiments). $\mathrm{ND}=$ not detectable. statistics; two-way ANOVA with multiple comparisons ${ }^{*} p<0.05,{ }^{* *} p<0.01,{ }^{* * *} p<0.001$. No significant differences were observed between SCID and NOD SCID mice -receiving hlgG2 or mlgG1. ANOVA, analysis of variance; NOD, non-obese diabetic; SCID, severe combined immunodeficient.

mice. Furthermore, the lack of a difference in SCID mice demonstrates that rapid hIgG clearance does not result from the absence of endogenous IgG or immune deficiency per se.

\section{Rapid mAb clearance in NOD SCID mice is isotype dependent and requires both SCID and NOD genotypes}

To determine if rapid mAb clearance in NOD SCID mice extended beyond hIgG1, isotype switch variants of rituximab were generated and administered to SCID or NOD SCID mice. Similar to hIgG1, mIgG2a also had a significantly faster $\mathrm{mAb}$ clearance in NOD SCID mice (figure 1D), being no longer detectable in the plasma by
A)

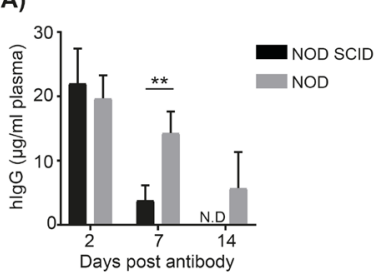

)

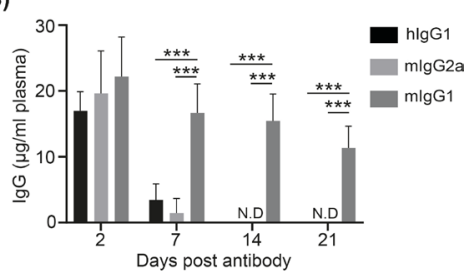

C)

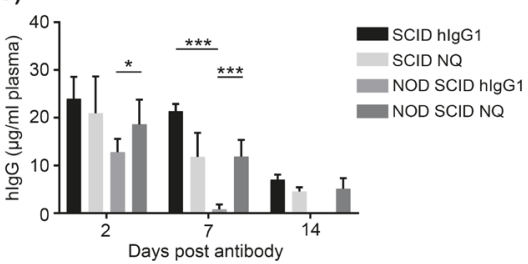

Figure 2 Rapid antibody half-life requires both the NOD and SCID phenotypes as well as functional Fc. (A) $100 \mu \mathrm{g}$ cetuximab was injected I.P. into NOD or NOD SCID mice with the concentration of hlgG in the plasma determined by ELISA, over 14 days. $(n=4-6)$. (B) $100 \mu g$ rituximab hlgG1, mlgG1 or mlgG2a was injected I.P. into NSG mice and the concentration of mouse or human IgG in the plasma determined by ELISA, $(n=6-8)$, data combined from two independent experiments. (C) $100 \mu \mathrm{g}$ rituximab (hlgG1) or rituximab hlgG1 N297Q (NQ) was injected I.P. into SCID or NOD SCID mice and the concentration of hlgG in the plasma determined by ELISA. (SCID $n=3-4$, NOD SCID $\mathrm{n}=7$ combined from two independent experiments). Twoway ANOVA with multiple comparisons, ${ }^{\star} p<0.05,{ }^{* *} p<0.01$, ${ }^{\star \star \star} \mathrm{p}<0.001$. ANOVA, analysis of variance; NOD, non-obese diabetic; SCID, severe combined immunodeficient.

day 14. In contrast, hIgG2 and mIgG1 had similar clearance rates in both strains. These results demonstrate that faster mAb clearance in NOD SCID mice is isotype dependent.

We next assessed whether the rapid IgG clearance occurred in NOD and NSG strains. NOD mice had a normal hIgG1 clearance rate, akin to that seen in SCID and BALB/c (figure 2A). However, NSG mice displayed rapid clearance, comparable to that in NOD SCID mice (figure 2B). These data demonstrate that both NOD and SCID phenotypes are necessary to confer rapid IgG clearance. Moreover, the differences between isotypes in NOD SCID mice also occurred in the NSG strain, with hIgG1 and mIgG2a but not mIgG1 exhibiting rapid clearance (figure 2B).

\section{Rapid hlgG1 clearance is dependent on Fc $\gamma \mathrm{R}$ binding}

Given that mIgG2a and hIgG1 have similar Fc $\gamma \mathrm{R}$ binding profiles (binding to all $\mathrm{mFc} \gamma \mathrm{R}$, with substantial affinity for several activatory Fc $\gamma \mathrm{R}$ ), we hypothesized that the rapid $\mathrm{mAb}$ clearance of hIgG1 and mIgG2a isotypes in NOD SCID mice was mediated by Fc $\gamma \mathrm{R} .{ }^{25}{ }^{26}$ This was investigated using a N279Q (NQ)-mutant of rituximab which lacks glycosylation at N297 and does not robustly engage $\mathrm{mF} \gamma \mathrm{R}$ (without compromising interaction with $\mathrm{FcRn}$ ). ${ }^{27}$ The NQ-mutant remained present in the plasma of NOD SCID mice at significantly higher concentrations at all time-points, supporting $\mathrm{mFc} \gamma \mathrm{R}$ involvement in the rapid 
hIgG1 clearance in NOD SCID mice (figure 2C). Moreover, the concentration of rituximab-NQ was comparable between SCID and NOD SCID mice at all time-points suggesting that abrogation of $\mathrm{mFc} \gamma \mathrm{R}$ binding restored normal mAb clearance rate.

\section{SCID and NOD SCID mice have comparable Fc $\gamma$ R expression levels}

Having established that the rapid hIgG1 clearance rate in NOD SCID mice was likely dependent on $\mathrm{mFc} \gamma \mathrm{R}$, the relative expressions levels of these receptors in SCID and NOD SCID mice was investigated (figure 3A). While there were no statistically significant differences in expression levels (two-way analysis of variance $p>0.05$ ) trends toward differential expression were observed. mFc $\gamma$ RII expression was lower on both $\mathrm{Ly} 6 \mathrm{C}^{\mathrm{Hi}}$ and $\mathrm{Ly} 6 \mathrm{C}^{\mathrm{Lo}}$ monocytes in NOD SCID compared with SCID mice (figure 3B). Neutrophil and splenic macrophage Fc $\gamma$ RIII expression was higher in SCID mice, with a similar expression profile for BMDM (online supplementary figure $3 \mathrm{a}$ ). The expression of $\mathrm{mFc} \gamma \mathrm{RI}$ was not investigated as it is known to contain multiple polymorphisms in NOD SCID mice which prevent its detection using available antibodies. ${ }^{28}$ The subtle differences in activatory $\mathrm{mFc} \gamma \mathrm{R}$ expression detailed above appear to be compensatory with a similar overall expression of activatory $\mathrm{mFc} \gamma \mathrm{R}$ in each strain. In summary, only monocyte Fc $\gamma$ RII was found to differ between SCID and NOD SCID mice; the relevance of this to $\mathrm{mAb}$ clearance rate remains to be determined.

\section{Rapid hlgG1 clearance in NOD SCID mice is dependent on Fc $\gamma$ RII}

To understand the contribution of specific $m F c \gamma R$ to rapid antibody clearance in NOD SCID mice, we made use of animals lacking different classes of $\mathrm{mF} \gamma \mathrm{R}$. In NOD SCID FcR $\gamma$-/- mice (which express no activatory Fc $\gamma R$ at the cell surface ${ }^{29}$ ) there was no significant difference in the concentration of hIgG1 over time compared with NOD SCID mice (figure 4A), demonstrating that a lack of activatory $\mathrm{mFc} \gamma \mathrm{R}$ does not influence hIgG1 clearance. However, in NOD SCID mice deficient in the inhibitory $\mathrm{mF} \gamma \gamma \mathrm{RII}$, the concentrations of hIgG1 were significantly increased compared with wild-type NOD SCID mice retaining $\mathrm{mFc} \gamma \mathrm{RII}$ (figure $4 \mathrm{~B}$ ) and comparable with SCID mice. These results demonstrate that the rapid hIgG1 clearance in NOD SCID mice is dependent on mFcyRII. Moreover, this result suggests that the somewhat reduced Fc $\gamma$ RII expression seen previously in NOD SCID mice is not responsible for the fast hIgG1 clearance rate.

\section{The polymorphic variants of $\mathrm{mFc} \gamma \mathrm{RII}$ have comparable affinity for hlgG1}

A number of autoimmune strains including NOD express the ly17.1 form of mFc $\gamma$ RII while most other in-bred strains, including BALB/c, express the ly17.2 variant. ${ }^{30}$ These two polymorphic forms vary in four amino acids, three of which are located in the extracellular domain. ${ }^{30}$ The extracellular domain of Fc $\gamma$ RII from SCID and NOD
SCID mice was cloned and expressed; their relative affinity for IgG was then determined by SPR. Neither heat aggregated, pooled hIgG or individual isotypes of IgG displayed substantially different binding affinities to the ly17.1 and ly17.2 variants (table 1).

\section{Absence of hematopoietic $\mathrm{mFc} \gamma \mathrm{R}$ Il or phagocytes does not restore normal $\mathrm{mAb}$ clearance}

$\mathrm{mF} \gamma \mathrm{RII}$ is expressed on both hematopoietic and nonhematopoietic cells. ${ }^{30}$ We, therefore, sought to determine which $\mathrm{mFc} \gamma \mathrm{RII}$-expressing cells were responsible for the rapid clearance of hIgG1. Accordingly, NOD SCID mice were irradiated and reconstituted with bone marrow from NOD SCID Fc $\gamma$ RII-/- mice (figure 4C,D). These mice, reconstituted with hematopoietic cells lacking mFcrRII displayed rapid clearance of hIgG1 and mIgG2a, indicating that mFc $\gamma \mathrm{RII}$ on cells of the

\section{A)}

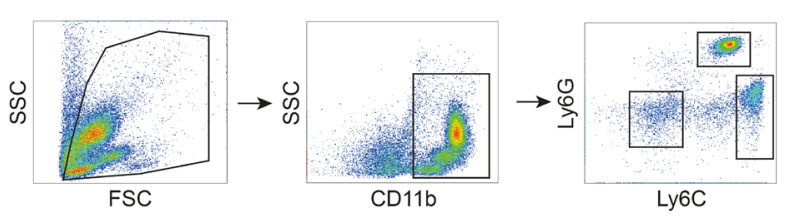

B)

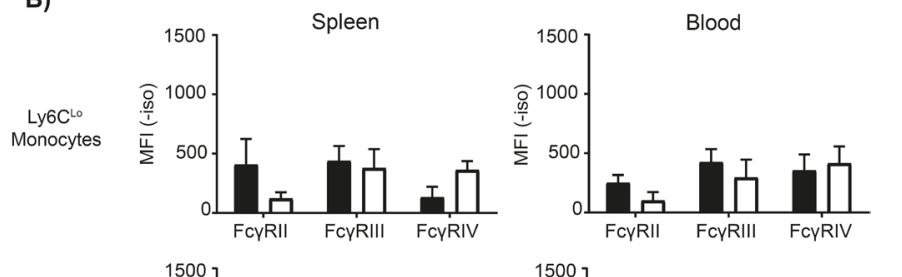

Ly6C $\mathrm{C}^{\mathrm{Hi}}$
Monocytes
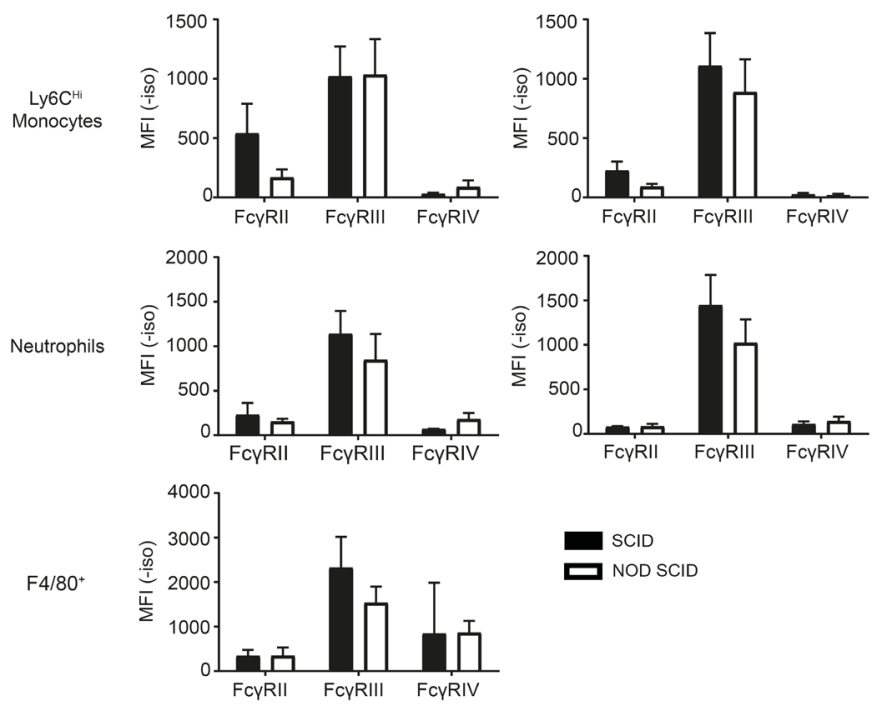

Figure $3 \mathrm{mFc} \gamma \mathrm{R}$ expression profiling in SCID and NOD SCID mice. Splenocytes or peripheral blood from SCID and NOD SCID mice were stained with specific antibodies for Ly6C, Ly6G, CD11b or CD11c to identify monocytes, macrophages and neutrophils, concurrently with mAb to each $\mathrm{mFc} \gamma \mathrm{R}$. $\mathrm{n}=3$ combined data from two independent experiments, mean+range. No statistically significant differences were observed between strains (two-way ANOVA with Tukeys multiple comparison test, $p>0.05$ ). ANOVA, analysis of variance; Fc $\gamma R$, Fc $\gamma$ receptors; $m A b$, monoclonal antibodies; NOD, non-obese diabetic; SCID, severe combined immunodeficient. 
A)

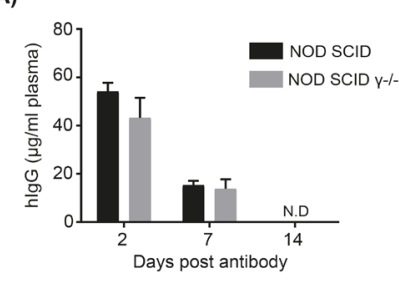

B)

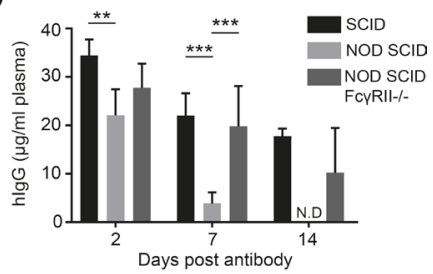

C)

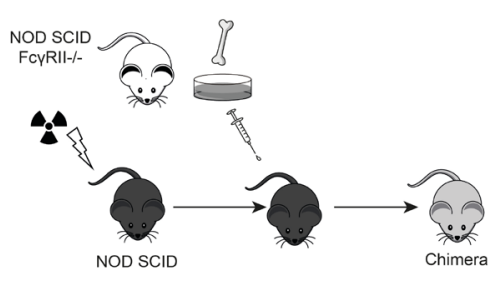

D)
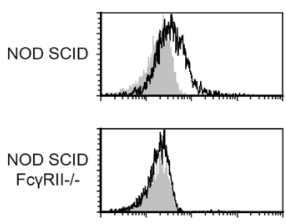

Chimera

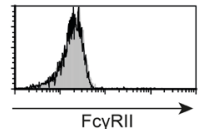

E)
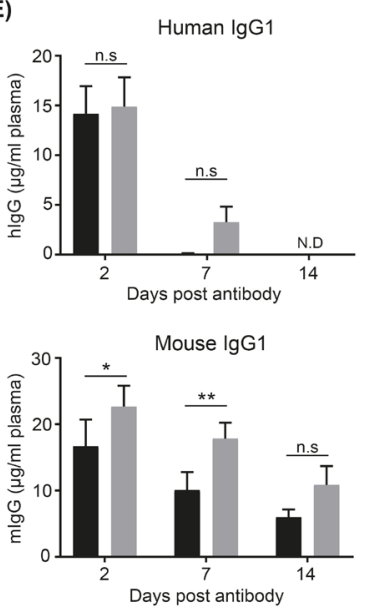

F)
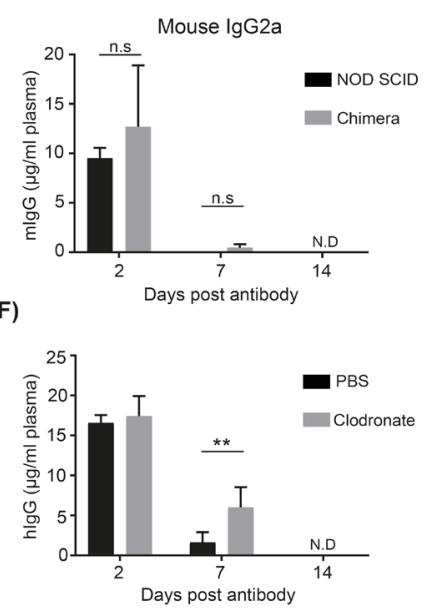

Figure 4 Rapid mAb clearance in NOD SCID mice is dependent on expression of $\mathrm{mFc} \gamma \mathrm{RI}$ but not activatory mFc $\gamma R$. (A) NOD SCID and NOD SCID FcR $\gamma$-chain deficient mice $(\gamma-/-)$ were injected with $100 \mu \mathrm{g}$ trastuzumab hlgG1 I.V. Tail blood was collected and the concentration of hlgG in the plasma determined by ELISA. $(n=3-4)$ mean+SD. By day $14 \mathrm{hlgG}$ was not detectable in the plasma of both strains. (B) SCID, NOD SCID and NOD SCID mFc $\gamma R$ RII-/- mice were injected with $100 \mu \mathrm{g}$ cetuximab I.V. The concentration of hlgG in plasma was determined 2, 7 and 14 days later by ELISA. ( $n=3-4$ per group), representative of two independent experiments. Two-way ANOVA with multiple comparisons ${ }^{*} p<0.05{ }^{* *} p<0.01,{ }^{* * *} p<0.001$. (C) NOD SCID mice were irradiated and reconstituted with bone marrow cells harvested from NOD SCID FcyRII-/- mice. (D) Engraftment was confirmed by staining peripheral CD11b+ cells for mFcyRII expression. (E) $100 \mu \mathrm{g}$ rituximab hlgG1 or mlgG2a was injected into these or control NOD SCID mice. The concentration of human or mouse IgG in the plasma was determined by ELISA. ( $n=3-4)$, mean+SD. (F) NOD SCID mice were injected I.V. with clodronate-containing or PBScontaining liposomes on days $-3,-1,6$ and 13 to deplete macrophages. On day $0,100 \mu \mathrm{g}$ rituximab was administered I.P. and the concentration of hlgG in the plasma determined by ELISA. ANOVA, analysis of variance; Fc $\gamma R$, Fc $\gamma$ receptors; mAb, monoclonal antibodies; NOD, non-obese diabetic; n.s, not significant; SCID, severe combined immunodeficient.
Table 1 Affinity of $\mathrm{mFc \gamma RIl}$ variants for IgG subtypes

\begin{tabular}{lll}
\hline & $\begin{array}{l}\text { NOD SCID } \\
\text { KD }\left(\mathbf{M} \times \mathbf{1 0}^{-6}\right)\end{array}$ & $\begin{array}{l}\text { SCID } \\
\text { KD }\left(\mathbf{M} \times \mathbf{1 0}^{-6}\right)\end{array}$ \\
\hline Aggregated hlgG & 0.13 & 0.15 \\
Cetux hlgG1 & 4.38 & 5.42 \\
Ritux hlgG1 & 2.50 & 3.18 \\
Ritux hlgG2 & 4.82 & 4.65 \\
Ritux mlgG1 & 2.25 & 2.02 \\
Ritux mlgG2a & 2.43 & 2.63 \\
\hline
\end{tabular}

Recombinant mFcyRII extracellular domains from SCID or NOD SCID mice were captured on a Biacore CM5 chip using an immobilized anti-HIS antibody. IgG of specific isotypes or heat aggregated, pooled hlgG was flowed over the chip and the KD value calculated using Biacore evaluation software. Fc $\gamma R$, Fc $\gamma$ receptors; NOD, non-obese diabetic; SCID, severe combined immunodeficient.

hematopoietic system were not responsible for the rapid $\mathrm{mAb}$ clearance (figure $4 \mathrm{E}$ ). We next considered whether phagocytes, particularly tissue resident macrophages, might be responsible and so deleted them with clodronate liposomes. This approach effectively removed macrophages (online supplementary figure 3b) but only resulted in a small increase in circulating hIgG1 7 days after mAb administration, with no hIgG1 detectable by day 14 (figure 4F). This suggests that phagocytes in NOD SCID mice are not primarily responsible for the rapid hIgG1 clearance and that a non-hematopoietic cell type is responsible. Given their high expression of $\mathrm{mFc} \gamma \mathrm{RII}$, the liver sinusoidal endothelial cells (LSEC) seem the most likely candidate. ${ }^{31}$ We confirmed high expression of mFc $\gamma$ RII on these cells by immunofluorescence of livers from both BALB/c and NOD SCID mice (online supplementary figure $4 \mathrm{a}$ and b). Moreover, we found $\mathrm{hIgG}$ detectable at substantially higher levels within the liver of NSG than SCID mice following administration of hIgG1 $\mathrm{mAb}$ confirming a role for the liver as a site of hIgG1 accumulation (online supplementary figure 4c).

\section{NOD SCID mice have reduced FcRn expression}

As mFcyRII is not known to directly regulate $\mathrm{mAb}$ clearance, we next considered whether FcRn might be involved in the process of controlling clearance rate in the NOD SCID mouse. Importantly, FcRn in NOD SCID mice does not to contain any sequence variations compared with other strains and has normal binding to both human and mouse IgG. ${ }^{14}$ However, qPCR revealed significantly lower FcRn transcription in both spleen and liver of NOD SCID versus SCID mice (figure 5A). This result was confirmed at the protein level by western blotting (figure 5B) and flow cytometry using the MST-HN protein which maintains FcRn binding at both acidic and neutral pH (figure 5C). ${ }^{32}$ This latter approach demonstrated a lower expression of FcRn in Ly6C+monocytes from NSG compared with SCID mice (MFI 354vs 3061, mean of $n=4)$. Combined, these results demonstrate that 
A)

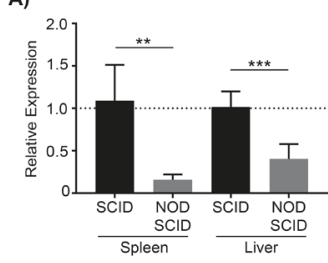

B)
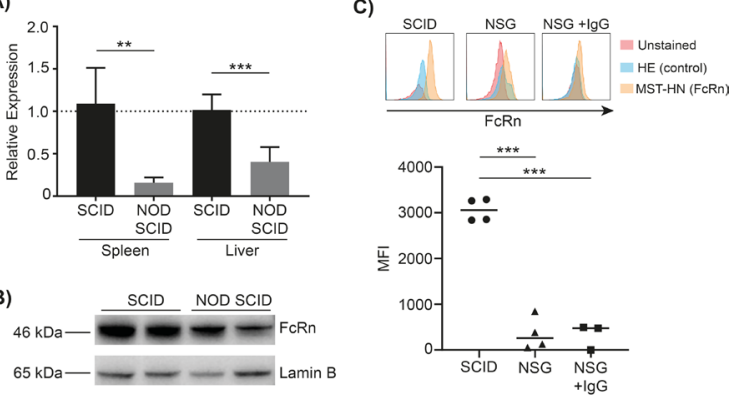

D)

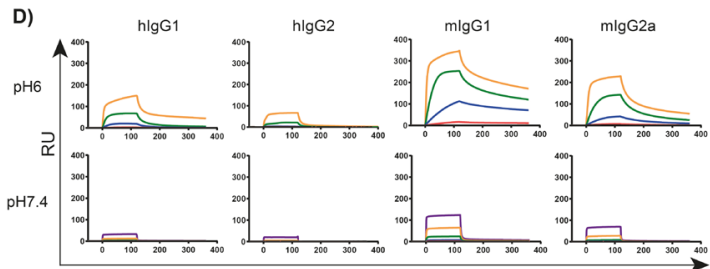

E)
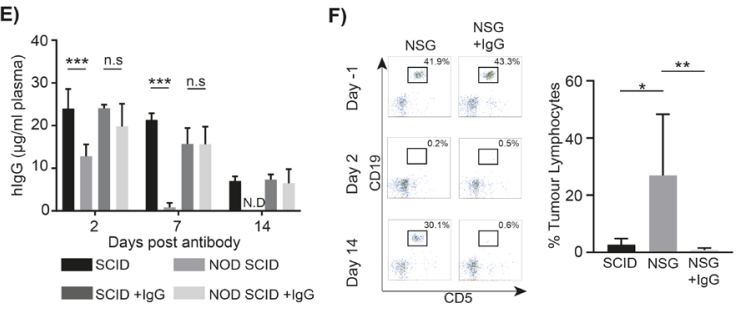

Figure 5 NOD SCID mice have low expression of FcRn, associated with rapid mAb clearance, which can be overcome by IgG reconstitution. (A) cDNA was produced from SCID and NOD SCID spleen and liver lysates with FcRn transcript expression analyzed by qPCR using the ddCT method and expressed relative to that in SCID mice. $(n=4-5)$, unpaired t-test ${ }^{* *} p<0.01,{ }^{* \star *} p<0.001$. (B) Splenocytes from SCID and NOD SCID spleens were lysed and Western blot performed on the lysates for FcRn and Lamin B as a loading control. (C) Uptake of MST-HN Abdeg by splenocytes from SCID and NSG mice as well as mlgG reconstituted NSG mice, gated on CD11b+Ly6G-Ly6C+cells. No protein (red), H435A control (blue) and MST-HN (orange) are shown. $\mathrm{N}=3-4$ with a representative example for each group shown. (D) Rituximab hlgG1, hlgG2, mlgG1 or mlgG2a was immobilized on Biacore CM5 chips and recombinant mFcyRII flowed over the chip at $\mathrm{pH} 6$ or $\mathrm{pH} 7.4$ with a highest receptor concentration of $1000 \mathrm{nM}$ and 5-fold serial dilutions. (E) SCID or NOD SCID mice were reconstituted with $400 \mu \mathrm{g} \mathrm{mlgG2a}$ and $500 \mu \mathrm{g}$ mlgG1 on day 0 . An additional $200 \mu \mathrm{g}$ mlgG2a was given on day $3,6,9,12$ and $15.100 \mu \mathrm{g}$ rituximab was then given I.P. on day 0 and the concentration of hlgG in the plasma determined by ELISA. $(n=4-8)$, data combined from two independent experiments, mean+SD. Two-way ANOVA with multiple comparisons ${ }^{* *} p<0.001$, n.s. $=$ not significant. (F) $\mathrm{E} \mu$-Tcl1 tumor cells were injected I.P. into SCID or NSG mice. Once tumor was detectable in the peripheral blood a group of NSG mice were reconstituted with mlgG as described above, animals were then treated with $100 \mu \mathrm{g}$ hlgG1 anti-mCD20 (18B12) I.P. representative flow cytometry plots are shown on the left. Fourteen days after treatment, the percentage of tumor cells in the blood was assessed and plotted. ( $n=5-6$ per group), mean+SD. One-way ANOVA with multiple comparisons ${ }^{*} p<0.05,{ }^{* *} p<0.01$. ANOVA, analysis of variance; Fc $\gamma R$, Fc $\gamma$ receptors; NOD, non-obese diabetic; NSG, NOD SCID interleukin-2 $\gamma-/-;$ SCID, severe combined immunodeficient. there is a lower expression of FcRn in the tissues known to be important for IgG recycling (spleen and liver) of NOD SCID mice compared with SCID. ${ }^{33} \mathrm{mFc} \gamma \mathrm{RII}$ has a $\mathrm{pH}$ dependent affinity for IgG isotypes and is expressed on the same cell types as FcRn.

While reduced FcRn could explain rapid IgG clearance, it does not provide an explanation for the isotype dependent nature of the effects seen, as all isotypes should be affected equally. In contrast, $\mathrm{mFc} \gamma \mathrm{RII}$ is known to display differential affinity for IgG isotypes (high for mIgG1, low for mIgG2a and hIgG1) and so we considered if mFc $\gamma$ RII specificity might be involved in regulating the clearance of the different isotypes. Using SPR and two different $\mathrm{mAb}$ of each isotype, we confirmed that at $\mathrm{pH} 7.4 \mathrm{mFc} \gamma \mathrm{RII}$ had $\sim 10$-fold higher affinity for mIgG1 $\left(2.74 \times 10^{-7} \mathrm{M}\right)$ vs mIgG2a $\left(1.18 \times 10^{-6} \mathrm{M}\right)$ and hIgG1 $\left(3.02 \times 10^{-6}\right)$ while the affinity for hIgG2 was lower still $\left(7.65 \times 10^{-6} \mathrm{M}\right)$ (table 2 and figure 5D).

We next considered that mFcyRII might internalize cell-surface bound IgG and by virtue of its higher affinity, preferentially protect mIgG1 from degradation following internalization. To do this, it would need to remain bound to IgG in a low $\mathrm{pH}$ environment, akin to FcRn. We therefore repeated SPR analysis at $\mathrm{pH6.0}$, and revealed that $\mathrm{mFc} \gamma \mathrm{RII}$ retained binding at low $\mathrm{pH}$, with affinity for mIgG1, mIgG2a and hIgG1 100-fold higher than at pH7.4. Notably, the KD for mIgG1 binding mFc $\gamma$ RII was $2.77 \times 10^{-9} \mathrm{M},>10$-fold higher than for hIgG1 and mIgG2a. This suggests that mFc $\gamma \mathrm{RII}$ is capable of binding IgG at an acidic $\mathrm{pH}$ with the potential to protect IgG from degradation being greatest for mIgG1. Using previously published affinity data for IgG binding to $\mathrm{mFcRn}$, we calculated the ratio of $\mathrm{mFc} \gamma \mathrm{RII}: \mathrm{FcRn}$ binding for different isotypes at pH6.0 (table 2 and figure 5D).$^{34}$ hIgG2 exhibited a high mFc $\gamma$ RII:FcRn ratio, suggesting preferential binding for FcRn at an acidic pH. In comparison, hIgG1 had a ratio around 1 (indicating no overall preference) whereas mIgG1 had a low ratio, preferentially binding with a higher affinity to $\mathrm{mFc} \gamma \mathrm{RII}$ than to FcRn.

Having hypothesized that the differential interaction with FcRn and FcyRII may play a role in the recycling of $\mathrm{IgG}$, and with the knowledge that the liver expresses $75 \%$ of the FcyRII in the mouse, we sought to determine the distribution of these two receptors within the liver. $^{31}$ The majority of mFc $\gamma$ RII was expressed by LSEC as determined by their morphology (online supplementary figure 4 ). We did not see $\mathrm{mFc} \gamma \mathrm{RII}$ onClec $4 \mathrm{~F}^{+} \mathrm{Kupffer}$ cells or Cytokeratin $8^{+}$hepatocytes. This is consistent with a previous study reporting $90 \%$ of the liver mFc $\gamma$ RII as being expressed by LSEC when assessing immunofluorescence by pixel intensity. ${ }^{31}$ We found FcRn to be widely expressed throughout the liver including on Kupffer cells and hepatocytes (online supplementary figure 4). This is consistent with a previous report showing FcRn mRNA in various cell types, additionally identifying LSEC as having the highest expression level. ${ }^{31}$ Together, these results suggest that LSEC may be the predominant cell type coexpressing Fc $\gamma$ RII and FcRn. 
Table 2 Affinity of $\mathrm{mFc} \gamma \mathrm{RII}$ and $\mathrm{mFcRn}$ for IgG subtypes

\begin{tabular}{|c|c|c|c|c|}
\hline & $\begin{array}{l}\text { FcyRII } \\
\text { KD pH7.4 (M) }\end{array}$ & $\begin{array}{l}\text { FcyRII } \\
\text { KD pH6 (M) }\end{array}$ & $\begin{array}{l}\text { Published FcRn } \\
\text { KD pH6 (M) }\end{array}$ & $\begin{array}{l}\text { KD ratio Fc } \gamma R I I / \\
\text { FcRn }\end{array}$ \\
\hline hlgG1 \#1 & $3.02 \times 10^{-6}$ & $4.92 \times 10^{-8}$ & $7.2 \times 10^{-8}$ & 0.68 \\
\hline hlgG2 \#1 & $7.65 \times 10^{-6}$ & $2.10 \times 10^{-7}$ & $6.3 \times 10^{-8}$ & 3.33 \\
\hline hlgG2 \#2 & $1.45 \times 10^{-5}$ & $2.18 \times 10^{-7}$ & $6.3 \times 10^{-8}$ & 3.46 \\
\hline mlgG2a \#1 & $1.18 \times 10^{-6}$ & $2.36 \times 10^{-8}$ & $4.9 \times 10^{-7}$ & 0.054 \\
\hline mlgG2a \#2 & $1.10 \times 10^{-6}$ & $2.41 \times 10^{-8}$ & $4.9 \times 10^{-7}$ & 0.049 \\
\hline
\end{tabular}

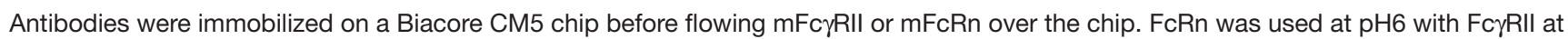
$\mathrm{pH} 6$ and $\mathrm{pH}$ 7.4. KD was calculated using Biacore evaluation software.

Fc $\gamma R$, Fc $\gamma$ receptors.

Overall, these data provided the possibility that antibody clearance in NOD SCID strains is controlled through differential engagement of the various isotypes by $\mathrm{mFc} \gamma \mathrm{RII}$ and FcRn. However, these effects have not been reported previously in standard in-bred strains, or the single NOD and SCID strains, indicating that the proposed pathway, which is at least in part mediated by isotype-dependent binding of $\mathrm{mFc} \gamma \mathrm{RII}$, is only revealed in the absence of endogenous IgG.

\section{Rapid hlgG1 clearance and reduced mAb efficacy can be overcome by IgG reconstitution}

We, therefore, hypothesized that the addition of exogenous mIgG would restore normal mAb clearance rate in NOD SCID mice. Accordingly, SCID and NOD SCID mice were reconstituted with mIgG1 and mIgG2a to a level equivalent to that seen in the plasma of wild type BALB/c mice (online supplementary figure 5). Subsequently, the clearance of hIgG1 was investigated (figure 5E). Reconstitution with mIgG overcame the rapid clearance of hIgG1 in NOD SCID mice such that it became comparable to that observed in SCID mice. In contrast, mIgG addition did not significantly alter the clearance of hIgG in SCID mice. Additionally, reconstitution with $\mathrm{mIgG}$ substantially reduced the accumulation of hIgG in the liver (online supplementary figure 4c). Importantly, the expression of FcRn was not altered by reconstitution with $\mathrm{mIgG}$ (figure 5C). Finally, we sought to determine if overcoming rapid clearance of hIgG1 by mIgG reconstitution could improve therapy, using an E $\mu$-TCL1 tumor and a hIgG1 antibody targeting mouse CD20 (18B12). Using this second tumor model we found the differences in duration of therapy between SCID and NSG mice was maintained, with tumor growth recurring in NSG before SCID mice (figure $5 \mathrm{~F}$ ). We then compared the duration of tumor deletion in NSG mice versus NSG mice reconstituted with $\mathrm{mIgG}$, using the same protocol as before. Reconstitution with mIgG was able to overcome the impaired therapy and restored comparable levels of tumor deletion and control to that observed in SCID mice both in terms of tumor percentage (figure $5 \mathrm{~F}$ ) and number of tumor cells (online supplementary figure 6). This demonstrates that reconstitution with $\mathrm{mIgG}$ is able to restore $\mathrm{mAb}$ efficacy in NSG mice.

\section{DISCUSSION}

Our observations with rituximab showed reduced tumor control in NOD SCID compared with SCID mice. Given that equivalent initial tumor clearance was observed, and deletion is known to be dose dependent, this impairment was considered to be a direct result of reduced serum persistence and insufficient $\mathrm{mAb}$ at later time points. ${ }^{35} 36$ Rituximab is a type I mAb, known to be internalized through cis-binding to Fc $\gamma$ RII following target binding, reducing its efficacy. ${ }^{18} 37$ Importantly, reduced tumor control was also seen with a type II anti-CD20 reagent, BHH2, indicating $\mathrm{mAb}$ internalization was not causal and that a separate phenomenon related to the mouse strain was responsible. In support of this, rapid clearance of wild-type and chimeric hIgG1 mAb was described recently in both NOD SCID and NSG mice. ${ }^{14} 16$ Furthermore, we saw the same rapid hIgG1 clearance for two additional hIgG1 mAb, lacking targets in the mouse, showing this phenomenon to be independent of the presence of tumor and unrelated to $\mathrm{F}(\mathrm{ab})$-mediated antigen binding.

Separately, both SCID and NOD mice had normal clearance of hIgG1, comparable to that of immune competent $\mathrm{BALB} / \mathrm{c}$ mice, as reported previously. ${ }^{24}$ This indicated that the genetic background of NOD mice, coupled with a lack of endogenous IgG (as a result of the SCID mutation) combined to elicit rapid hIgG1 clearance in NOD SCID mice. Importantly, our observations were replicated in NSG mice, indicating that rapid hIgG1 clearance is a feature of all NOD SCID derived strains. mIgG1 was found to have normal clearance in NOD SCID mice, whereas both hIgG1 and mIgG2a had short half-lives. Both humans and mice have multiple activatory $\mathrm{Fc} \gamma \mathrm{R}$, but a single inhibitory receptor, Fc $\gamma$ RII (FcyRIIb in humans). These receptors interact differentially with the various mouse and human 
IgG isotypes: mIgG2a and hIgG1 bind preferentially to multiple activatory receptors and as such have high activatory:inhibitory (A:I) ratios. ${ }^{26}$ In contrast, mIgG1 exhibits binding to only a single activatory $\mathrm{Fc} \gamma \mathrm{R}$ (Fc $\gamma \mathrm{RIII}$ ) while retaining binding to Fc $\gamma$ RII, yielding a corresponding low A:I ratio. ${ }^{38}$ These observations provided a potential clue toward the isotype-based effects observed. A role for $\mathrm{F} \gamma \gamma \mathrm{R}$ in this process was subsequently confirmed by using a hIgG1 N297Q mAb which abrogates binding to Fc $\gamma$ Rs. ${ }^{27}$ Importantly, the N297Q mutation has been demonstrated not to alter hIgG1 clearance in immune compromised mice. ${ }^{27}$ The normal clearance rate of $\mathrm{N} 297 \mathrm{Q} \mathrm{mAb}$ in NOD SCID mice suggested that the rapid clearance of hIgG1 (and mIgG2a) in NOD SCID mice was dependent on Fc:Fc $\gamma \mathrm{R}$ interaction.

Despite establishing a likely role for $\mathrm{mFc} \gamma \mathrm{R}$ in rapid $\mathrm{mAb}$ clearance, no gross changes in activatory Fc $\gamma \mathrm{R}$ expression levels were observed in NOD SCID versus SCID mice. The subtle interstrain differences in $\mathrm{mF} \gamma \gamma \mathrm{RIII}$ and $\mathrm{mFc} \gamma \mathrm{RIV}$ expression are likely to be compensatory and do not result in a large difference in the A:I ratio or amount of activatory Fc $\gamma \mathrm{R}$ on the cell surface. One caveat here was that the expression level of $\mathrm{mFc} \gamma \mathrm{RI}$ in NOD SCID mice could not be determined by flow cytometry as its sequence varies considerably from the canonical sequence seen in most other strains (by 17 residues), and so cannot be detected using our existing reagents. ${ }^{39} \mathrm{mFc} \gamma \mathrm{RII}$ expression was found to be lower on monocytes from NOD SCID compared with SCID mice, likely due to the previously reported alterations upstream of the gene in NOD SCID mice associated with lower expression. ${ }^{40}$ However, subsequent results, particularly in mice lacking $\mathrm{mFc} \gamma \mathrm{RII}$ expression, demonstrate that the reduced expression of $\mathrm{mF} \gamma \gamma \mathrm{RII}$ was unlikely responsible for the rapid $\mathrm{mAb}$ clearance.

We additionally investigated the expression levels of FcRn, the primary receptor responsible for IgG recycling and long half-life. ${ }^{41}$ While it has a broad tissue distribution, expression is particularly prominent in the spleen and liver. ${ }^{33}{ }^{41}$ Analysis of these tissues demonstrated that there was lower expression of FcRn in NOD SCID compared with SCID mice. SCID mice have previously been reported to have comparable FcRn expression and tissue distribution to immune-competent mice; indicating that the reduction is a result of the NOD phenotype rather than elevated expression in SCID mice. ${ }^{33}$ However, given that the N279Qmutated antibody which can interact with FcRn but not Fc $\gamma \mathrm{R}$ had a normal clearance rate in NOD SCID mice, the reduced FcRn expression in isolation cannot explain the differences in $\mathrm{mAb}$ clearance.

To determine the receptor responsible, we used mice deficient in either the activatory or inhibitory $\mathrm{mFc} \gamma \mathrm{R}$ by employing $\mathrm{mFcR} \gamma$-chain -/- or $\mathrm{mFc} \gamma \mathrm{RII}-/$ - mice, respectively. Only the absence of $\mathrm{mFc} \gamma \mathrm{RII}$ restored normal hIgG1 clearance in NOD SCID mice. This observation supports the implications of the N297Q-mutant data, that failure to engage with $\mathrm{mFc} \gamma \mathrm{RII}$ is important and therefore phenocopies the effect in the mFc $\gamma \mathrm{RII}-/$ - mice. Our observation that $\mathrm{mFc} \gamma \mathrm{RII}$ mediates this effect is in contrast to a previous study suggesting mFçRIV is responsible. ${ }^{16}$ The previous study used an Fc-engineered antibody reported to have reduced binding to Fc $\gamma$ RIV; such mutations often result in broader changes to $\mathrm{Fc} \gamma \mathrm{R}$ binding profiles with causal effects of specific Fc $\gamma R$ difficult to define. In contrast, in the present study we were able to specifically define the role of Fc $\gamma$ RII by using mice genetically deficient in Fc $\gamma$ RII.

Given the dependence on mFc $\gamma R$ II, we investigated this receptor in more detail. There are two polymorphic variants of $\mathrm{mFc} \gamma \mathrm{RII}$; the ly17.1 haplotype expressed by NOD SCID mice, and the more common ly17.2 haplotype expressed by most other in-bred mouse strains, which differ by four amino acids, three of which are extracellular. ${ }^{42}$ We confirmed previous observations that these allotypes do not differ in their affinity for IgG. While this SPR analysis assesses the likely effects of the extracellular polymorphisms, further investigation is needed into the role of the I258S intracellular polymorphism to determine its influence on $\mathrm{mAb}$ internalization. This could be of importance given the role of the intracellular I232T polymorphism in $\mathrm{hFc} \gamma \mathrm{RIIB}$, which alters the ability of the receptor to cluster into lipid rafts and deliver inhibitory signals. ${ }^{44}$

The data presented here indicate that no single factor can explain the isotype-dependent differences in $\mathrm{mAb}$ clearance in NOD SCID vs SCID mice. Instead, the data support a more complex model whereby multiple factors arising from the NOD and SCID backgrounds combine to deliver the observed defect. We propose a model whereby $m F c \gamma R I I$ accelerates initial $m A b$ internalization. The ability of Fc $\gamma$ RII to mediate mAb internalization has been previously reported in DC-mediated antigen presentation and the internalization of rituximab. ${ }^{37} 45$ hIgG1 N297Q

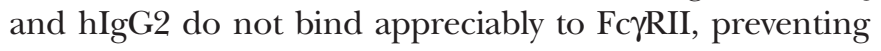
receptor-mediated internalization, maintaining equivalent clearance in both SCID and NOD SCID mice. Similarly, in SCID mice with a normal level of FcRn, the IgG internalized via Fc $\gamma$ RII can be efficiently recycled by FCRn to maintain serum persistence. However, In NOD SCID mice, this efficient FcRn mediated recycling does not occur due to the reduced FcRn expression levels, resulting in more rapid serum loss.

In trying to understand the isotype dependent nature of the rapid IgG clearance rate in NOD SCID mice, we unexpectedly observed an increased affinity of $\mathrm{mFc} \gamma \mathrm{RII}$ for all IgG at pH6.0. Crucially, however, the affinity of mFc $\gamma$ RII for mIgG1 at pH6.0 was retained and 10-fold higher than for the other isotypes investigated. This raises the possibility that mIgG1 is protected from degradation under acidic conditions due to continued association with $\mathrm{mF} \gamma \gamma \mathrm{RII}$ following internalization. In contrast, mIgG2a and hIgG1 would remain unprotected and become degraded following internalization, due to $\mathrm{mF} c \gamma \mathrm{RII}$ having lower affinity for these isotypes at $\mathrm{pH} 6.0$. We propose that this reduced degradation occurs only in the presence of reduced FcRn expression in NOD SCID mice, further work is, however, required to confirm this hypothesis. These data, therefore, suggest a complex role for Fc $\gamma \mathrm{RII}$ in $\mathrm{mAb}$ clearance; it is required for the internalization of $\operatorname{IgG}$, preventing external catabolism, yet it also delivers IgG for 
internal lysosomal degradation unless it exhibits sufficient affinity for IgG binding at pH6.0.

Prior experiments in conditional knock-out mice suggested that both endothelial and hematopoietic cells regulate IgG levels in mice. ${ }^{46} 47$ The transfer of $\mathrm{mF} \gamma \gamma \mathrm{RII}-/-$ NOD SCID bone marrow into NOD SCID mice resulted in mice deficient in hematopoietic $\mathrm{mFc} \gamma \mathrm{RII}$ but with $\mathrm{mFc} \gamma \mathrm{RII}$ expression on non-hematopoietic (predominantly endothelial) cells. hIgG1 clearance in these chimeras was unaltered compared with NOD SCID mice, demonstrating that hematopoietic cells were not responsible. The liver was previously found to be the main site of IgG clearance, accounting for $30 \%$ of all antibody degradation. ${ }^{48}$ The same organ has also been shown to contain $75 \%$ of the mFc $\gamma$ RII in the body, the receptor demonstrated here to be essential for rapid NOD SCID mAb clearance. ${ }^{31}$ Additionally, we were able to demonstrate greater accumulation of hIgG in the liver of NSG compared with SCID mice, an effect that was overcome by the addition of exogenous mIgG. Our immunofluorescence studies, combined with previous reports, suggest that LSEC are the predominant cell type in the liver expressing both Fc $\gamma \mathrm{RII}$ and FcRn, the receptors regulating the fast mAb clearance. ${ }^{31} 49$ LSEC have been described as having the highest rates of endocytic uptake in the body. In addition, $\mathrm{mFc} \gamma \mathrm{RII}$ is required for the efficient clearance of small immune complexes. ${ }^{31}{ }^{50}$ This leads us to hypothesize that LSEC are the key cell type responsible for fast $\mathrm{mAb}$ clearance observed in the present study, with internalization of IgG mediated by $\mathrm{mFc} \gamma \mathrm{RII}$.

Further investigation is required to determine if $\mathrm{pH}$ and isotype dependent affinity is restricted to $\mathrm{mFc} \gamma \mathrm{RII}$ or is common to the other $\mathrm{Fc} \gamma \mathrm{R}$. Moreover, it remains to be established if the same occurs with the inhibitory Fc $\gamma \mathrm{RIIb}$ in humans. This could have implications for $\mathrm{mAb}$ therapy as it is known that the A:I ratio of IgG binding to Fc $\gamma \mathrm{R}$ can determine the outcome of therapy, particularly where the expression of $\mathrm{hFc} \gamma \mathrm{RIIb}$ may increase, such as within the tumor microenvironment. ${ }^{51}$ Moreover, in this context, the acidic $\mathrm{pH}$ of the tumor microenvironment may further modify this ratio of A:I binding by altering the relative binding to individual receptors.

Given the importance of the rapid mAb clearance in NOD SCID mice on the therapeutic activity of direct targeting hIgG1 mAb, we sought a means of restoring normal pharmacokinetics. By reconstituting NOD SCID mice with physiological levels of $\mathrm{mIgG}$, the rapid $\mathrm{mAb}$ clearance could be overcome, restoring persistence equivalent to that observed in SCID and BALB/c mice. Moreover, this increased persistence of therapeutic $\mathrm{mAb}$ was able to recover anti-tumor efficacy to the same level as seen in SCID mice. This result is in agreement with findings that the addition of human IVIg can restore the normal half-life of an antibody-drug conjugate. ${ }^{16}$ Moreover, it has been previously reported that the addition of exogenous IgG is able to overcome anomalous antibody biodistribution in NOD SCID mice, adding to the potential benefits of $\operatorname{IgG}$ reconstitution in tumor models. ${ }^{17}$ We suggest that in the presence of exogenous IgG, mFc $\gamma \mathrm{RII}$ is occupied (most likely by the mIgG1 component, due to its higher affinity) and less internalization of hIgG1 can occur. Based on these observations, we propose that reconstitution with IgG should be a consideration when performing therapy experiments in NOD SCID mice in order to restore therapeutic antibody half-life.

The implications for the findings presented here are wide-reaching. With an increasing use of immunecompromised mice in preclinical investigation of $\mathrm{mAb}$ therapeutics, it is essential to understand how the choice of host strain can influence the outcome. The clearance rate of the most clinically relevant deleting isotypes are significantly shorter in NOD SCID and NSG mice than other immune-compromised strains such as SCID. This is likely to underplay the therapeutic efficacy of mAb used in these models and complicate comparisons between strains. Additionally, there are significant efforts ongoing to understand the isotype requirements for $\mathrm{mAb}$ directed against different targets, and with different $\mathrm{Fc}$ requirements. ${ }^{52}$ Our work suggests that NOD SCID mice may not be a suitable host strain for determining the optimal mAb isotype or therapeutic dose due to complications arising from different isotype-dependent clearance rates, unless exogenous $\mathrm{mIgG}$ reconstitution is also provided. Specifically, we suggest that caution should be exercised when interpreting results from immune compromised mice on the NOD SCID background with regard to differences in antibody activity that could be explained by mAb clearance rate.

Acknowledgements The authors would like to thank all of the members of the Antibody and Vaccine Group (Cancer Sciences, Faculty of Medicine, University of Southampton, UK), Professor Falk Nimmerjahn and Professor Sally Ward for helpful discussions relating to the experiments reported herein. SW additionally provided the Abdeg reagents for quantifying $\mathrm{FcRn}$ expression.

Contributors RJO, CIM, SJ, KLC and VAP performed experiments. RJO analysed the data. RJO, MSC and MJG interpreted the results. PJD and HTCC generated critical reagents. RJO and MSC wrote the manuscript.

Funding Funding was provided through an iCASE studentship to RJO and MSC with Huntingdon Life Sciences from the MRC (1254288), Programme Grants from Bloodwise (12050) and Cancer Research UK (A24721) as well as CRUK center support C328/A25139.

Competing interests MSC is a retained consultant for Bioinvent and has performed educational and advisory roles for Boehringer Ingelheim, Merck KGaA, Baxalta and GLG. He has received research funding from Bioinvent, Roche, Gilead, Iteos, UCB and GSK.

Patient consent for publication Not required.

Ethics approval Animal experiments were cleared through local ethics committees and performed according to Home Office guidelines under project license PB24EEE31.

Provenance and peer review Not commissioned; externally peer reviewed.

Data availability statement Data are available on reasonable request. All datasets used and/or analysed during the current study are available from the corresponding author on reasonable request.

Open access This is an open access article distributed in accordance with the Creative Commons Attribution Non Commercial (CC BY-NC 4.0) license, which permits others to distribute, remix, adapt, build upon this work noncommercially, and license their derivative works on different terms, provided the original work is properly cited, appropriate credit is given, any changes made indicated, and the use is non-commercial. See http://creativecommons.org/ licenses/by-nc/4.0/.

ORCID iD

Robert J Oldham http://orcid.org/0000-0002-8007-1145 


\section{REFERENCES}

1 Kaplon H, Reichert JM. Antibodies to watch in 2018. MAbs 2018;10:183-203

2 van der Loo JC, Hanenberg H, Cooper RJ, et al. Nonobese diabetic/ severe combined immunodeficiency (NOD/SCID) mouse as a model system to study the engraftment and mobilization of human peripheral blood stem cells. Blood 1998;92:2556-70.

3 Gerstein R, Zhou Z, Zhang H, et al. Patient-Derived xenografts (PDX) of B cell lymphoma in NSG mice: a mouse Avatar for developing personalized medicine. Blood 2015;126:5408.

4 Blunt T, Finnie NJ, Taccioli GE, et al. Defective DNA-dependent protein kinase activity is linked to $\mathrm{V}(\mathrm{D}) \mathrm{J}$ recombination and DNA repair defects associated with the murine scid mutation. Cell 1995;80:813-23.

5 Mouse strain datasheet-001303 NOD scid: the Jackson laboratory, 2020. Available: https://www.jax.org/strain/001303 [Accessed 26 Feb 2020].

6 Shultz LD, Schweitzer PA, Christianson SW, et al. Multiple defects in innate and adaptive immunologic function in NOD/LtSz-scid mice. $J$ Immunol 1995;154:180-91.

7 Brandsma AM, Hogarth PM, Nimmerjahn F, et al. Clarifying the Confusion between Cytokine and Fc Receptor "Common Gamma Chain". Immunity 2016;45:225-6.

8 Ito M, Hiramatsu H, Kobayashi K, et al. NOD/SCID/gamma(c)(null) mouse: an excellent recipient mouse model for engraftment of human cells. Blood 2002;100:3175-82.

9 Zalevsky J, Chamberlain AK, Horton HM, et al. Enhanced antibody half-life improves in vivo activity. Nat Biotechnol 2010;28:157-9.

10 Ravetch JV, Bolland S. Igg Fc receptors. Annu Rev Immunol 2001;19:275-90.

11 Roopenian DC, Akilesh S. Fcrn: the neonatal Fc receptor comes of age. Nat Rev Immunol 2007;7:715-25.

12 Raghavan M, Bonagura VR, Morrison SL, et al. Analysis of the $\mathrm{pH}$ dependence of the neonatal Fc receptor/immunoglobulin $\mathrm{G}$ interaction using antibody and receptor variants. Biochemistry 1995;34:14649-57.

13 Kim JK, Firan M, Radu CG, et al. Mapping the site on human IgG for binding of the MHC class I-related receptor, FcRn. Eur J Immunol 1999;29:2819-25.

14 Pop L, X-y L, Pop I, et al. Abnormally short serum half-lives of chimeric and human IgGs in NOD-SCID mice (P4184). The Journal of Immunology 2013;190:48.

15 Li F, Ulrich M, Hunter J, et al. Abstract 2082: Fc-Fc $\gamma R$ interaction impacts the clearance and antitumor activity of antibody-drug conjugates in NSG mice. Cancer Research 2016;76.

16 Li F, Ulrich ML, Shih VF-S, et al. Mouse strains influence clearance and efficacy of antibody and antibody-drug conjugate via Fc-Fc $\gamma R$ interaction. Mol Cancer Ther 2019;18:780-7.

17 Sharma SK, Chow A, Monette S, et al. Fc-Mediated anomalous biodistribution of therapeutic antibodies in immunodeficient mouse models. Cancer Res 2018;78:1820-32.

18 Tipton TRW, Roghanian A, Oldham RJ, et al. Antigenic modulation limits the effector cell mechanisms employed by type I anti-CD20 monoclonal antibodies. Blood 2015;125:1901-9.

19 Blunt MD, Carter MJ, Larrayoz M, et al. The PI3K/mTOR inhibitor PF-04691502 induces apoptosis and inhibits microenvironmental signaling in CLL and the E $\mu$-TCL1 mouse model. Blood 2015;125:4032-41.

20 Tutt AL, James S, Laversin SA, et al. Development and characterization of monoclonal antibodies specific for mouse and human Fc $\gamma$ receptors. J Immunol 2015;195:5503-16.

21 Williams EL, Tutt AL, French RR, et al. Development and characterisation of monoclonal antibodies specific for the murine inhibitory Fc $\gamma$ RIIB (CD32B). Eur J Immunol 2012;42:2109-20.

22 Cragg MS, Morgan SM, Chan HTC, et al. Complement-Mediated lysis by anti-CD20 mAb correlates with segregation into lipid rafts. Blood 2003;101:1045-52.

23 Cragg MS, Glennie MJ. Antibody specificity controls in vivo effector mechanisms of anti-CD20 reagents. Blood 2004;103:2738-43.

24 Zuckier LS, Georgescu L, Chang CJ, et al. The use of severe combined immunodeficiency mice to study the metabolism of human immunoglobulin G. Cancer 1994;73:794-9.

25 Nimmerjahn F, Ravetch JV. Divergent immunoglobulin G subclass activity through selective $\mathrm{Fc}$ receptor binding. Science 2005;310:1510-2.

26 Overdijk MB, Verploegen S, Ortiz Buijsse A, et al. Crosstalk between human IgG isotypes and murine effector cells. J Immunol 2012;189:3430-8.
27 Tao MH, Morrison SL. Studies of aglycosylated chimeric mousehuman IgG. Role of carbohydrate in the structure and effector functions mediated by the human IgG constant region. J Immunol 1989;143:2595-601.

28 Gavin AL, Leiter EH, Hogarth PM. Mouse FcgammaRI: identification and functional characterization of five new alleles. Immunogenetics 2000;51:206-11.

29 Takai T, Li M, Sylvestre D, et al. Fcr gamma chain deletion results in pleiotrophic effector cell defects. Cell 1994;76:519-29.

30 Smith KGC, Clatworthy MR. Fcgammariib in autoimmunity and infection: evolutionary and therapeutic implications. Nat Rev Immunol 2010;10:328-43.

31 Ganesan LP, Kim J, Wu Y, et al. Fc $\gamma$ RIlb on liver sinusoidal endothelium clears small immune complexes. J Immunol 2012;189:4981-8.

32 Vaccaro C, Zhou J, Ober RJ, et al. Engineering the Fc region of immunoglobulin $\mathrm{G}$ to modulate in vivo antibody levels. Nat Biotechnol 2005;23:1283-8.

33 Latvala S, Jacobsen B, Otteneder MB, et al. Distribution of FcRn across species and tissues. J Histochem Cytochem 2017;65:321-33.

34 Abdiche YN, Yeung YA, Chaparro-Riggers J, et al. The neonatal Fc receptor (FcRn) binds independently to both sites of the IgG homodimer with identical affinity. MAbs 2015;7:331-43.

35 Beers SA, Chan CHT, James S, et al. Type II (tositumomab) antiCD20 monoclonal antibody out performs type I (rituximab-like) reagents in B-cell depletion regardless of complement activation. Blood 2008;112:4170-7.

36 Beers SA, French RR, Chan HTC, et al. Antigenic modulation limits the efficacy of anti-CD20 antibodies: implications for antibody selection. Blood 2010;115:5191-201.

37 Vaughan AT, Iriyama C, Beers SA, et al. Inhibitory Fc $\gamma R$ IIlb (CD32b) becomes activated by therapeutic $\mathrm{mAb}$ in both cis and trans and drives internalization according to antibody specificity. Blood 2014:123:669-77.

38 Bruhns P, lannascoli B, England P, et al. Specificity and affinity of human Fcgamma receptors and their polymorphic variants for human IgG subclasses. Blood 2009;113:3716-25.

39 Prins JB, Todd JA, Rodrigues NR, et al. Linkage on chromosome 3 of autoimmune diabetes and defective Fc receptor for IgG in NOD mice. Science 1993;260:695-8.

40 Pritchard NR, Cutler AJ, Uribe S, et al. Autoimmune-Prone mice share a promoter haplotype associated with reduced expression and function of the Fc receptor FcgammaRII. Curr Biol 2000;10:227-30.

41 Roopenian DC, Christianson GJ, Sproule TJ, et al. The MHC class I-like IgG receptor controls perinatal IgG transport, IgG homeostasis, and fate of IgG-Fc-coupled drugs. J Immunol 2003;170:3528-33.

42 Hibbs ML, Hogarth PM, McKenzie IF. The mouse Ly-17 locus identifies a polymorphism of the Fc receptor. Immunogenetics 1985;22:335-48

43 Slingsby JH, Hogarth MB, Walport MJ, et al. Polymorphism in the Ly17 alloantigenic system of the mouse FcgRII gene. Immunogenetics 1997;46:361-2.

44 Kono H, Kyogoku C, Suzuki T, et al. Fcgammariib lle232Thr transmembrane polymorphism associated with human systemic lupus erythematosus decreases affinity to lipid rafts and attenuates inhibitory effects on B cell receptor signaling. Hum Mol Genet 2005;14:2881-92.

45 Bergtold A, Desai DD, Gavhane A, et al. Cell surface recycling of internalized antigen permits dendritic cell priming of B cells. Immunity 2005;23:503-14.

46 Montoyo HP, Vaccaro C, Hafner M, et al. Conditional deletion of the MHC class I-related receptor FcRn reveals the sites of IgG homeostasis in mice. Proc Natl Acad Sci U S A 2009;106:2788-93.

47 Ward ES, Zhou J, Ghetie V, et al. Evidence to support the cellular mechanism involved in serum IgG homeostasis in humans. Int Immunol 2003;15:187-95.

48 Eigenmann MJ, Fronton L, Grimm HP, et al. Quantification of IgG monoclonal antibody clearance in tissues. MAbs 2017;9:1007-15.

49 van der Flier A, Liu Z, Tan S, et al. Fcrn rescues recombinant factor VIII Fc fusion protein from a vWF independent FVIII clearance pathway in mouse hepatocytes. PLoS One 2015;10:e0124930-e.

50 Knolle PA, Wohlleber D. Immunological functions of liver sinusoidal endothelial cells. Cell Mol Immunol 2016;13:347-53.

51 Dahal LN, Dou L, Hussain K, et al. Sting activation reverses Lymphoma-Mediated resistance to antibody immunotherapy. Cancer Res 2017;77:3619-31.

52 White AL, Chan HTC, French RR, et al. Conformation of the human immunoglobulin G2 hinge imparts superagonistic properties to immunostimulatory anticancer antibodies. Cancer Cell 2015;27:138-48. 